\title{
WORK AND TIMING OF FIRST LIVE BIRTHS IN NEW ZEALAND
}

\author{
A. Dharmalingam, I. Pool and K. Johnstone
}

Population Studies Centre, University of
Waikato, Hamilton

\begin{abstract}
In this paper we have used data from a nationally representative sample survey of New Zealand women $(N=2673)$ aged between 20 and 59 years. We employ life-table technique and proportional hazard modelling to assess the role of individual and group level variables in determining the timing of first live births. This study suggests that a woman's decision to work and to have children and when to have them are intimately linked. While the age at which women obtain their first job has not changed much over the generations the age of the mother when her first child was born has risen considerably over recent generations. The result has been a widening period of time between the first job and the first child (for both Maori and nonMaori). Our analysis suggests that the number of years a woman has worked is very closely associated with when she has her first child. Having worked increases the chances of having a child, but as the work experience lengthens so this chance declines.
\end{abstract}

Demographic trends in New Zealand have generally followed the European and North American pattern. Nevertheless, the post-war demographic experience in New Zealand is different in two ways. Firstly, the baby-boom was prolonged and fertility levels were relatively high; and secondly, Maori and Pakeha fertility transitions have been spread over different periods (Pool and Sceats, 1981; Pool, 1991; Jackson and Pool, 1994). Despite these differences, current fertility levels of the two major ethnic groups in New Zealand are as low as those found among most developed countries.

Major social, economic and ideological changes have been posited as the driving force behind the secular declines in fertility levels in the developed world including New Zealand. In seeking explanations the determinants that have attracted most attention are formulated in terms of changes in women s labour force participation (Becker, 1960, 1981; Easterlin, 1978; Willis, 1974), ideational changes (Cleland and Wilson, 1987) and a matrimonial transition (van de Kaa, 1996).

In the conventional view, particular importance is attached to the simultaneous increase in the non-household economic activities among women and the decline in average family size and this is linked to increased levels of education among women. The argument is that those in the labour force, particularly those in most rewarding occupation, will use more effective means to prevent conception. This is in order firstly to complete their education prior to entering the labour market, and then to stay in employment until wellestablished in a career before embarking on childbearing. Thus any analysis of this issue must cover not only work per se, but education as its pre-determinant, and contraception as a mediating factor. This economic view has, however, been challenged by the diffusionist school (e.g. vande Walle, 1992; Knodel and van de Walle, 1979; Cleland and Wilson, 1987; Mauldin and Ross, 1991; Bongaarts, 1993) who favour intergenerational changes in attitudes, which are often attained by education. To capture this idea, van de Kaa (1996) referred to mental cohorts (ie. attitudinal and value changes).

A study of fertility change in Britain in the 1960s and 1970 s is the latest to question the predominance of economic factors (Murphy, 1993) and to suggest a third determinant. By using mcro-level time-series data from 1963-1980 for Britain, he has shown that 'macro-contraception' - the nexus of attitudes, values and norms surrounding the acceptance and actual use of contraception - is more important than the conventional view would suggest.

We investigate these different explanations, focusing on the role of work. This is examined in relation to a key determinant of employment opportunities, education. To complete education and to remain in the workforce efficient contraception must be employed for those exposed to intercourse (a very high proportion of women in the survey had everbeen exposed and most were currently exposed). At the same time we examine alternative hypotheses, using cohort differentials as an indicator of ideational shifts.

The data set available to us also permits us to analyse the use of contraception at first intercourse, and this permits us to analyse the use of contraception at first intercourse, and this allows us not only evaluate its macro-role as seen for cohorts (and thus to test the ideational hypotheses) as well as its micro-role as a mechanism, but also because its use indicates 
a desire to avoid breaks in education and/or work.

In this paper, we employ micro-level data to analyse the relationship between work and the timing of first births in New Zealand. Here we treat work as an explanatory variable and assess its effect on the timing of first birth, not vice versa. Our analysis is based on the data collected in a nationally representative survey among women in New Zealand. This was carried out in 1995 by the Population Studies Centre, University of Waikato (Marsault et al., forthcoming).

\section{Data}

The analysis of reproduction and related issues in New Zealand has been restricted by the fact that the only nationallevel data came from the census or vital registrations (Pool and Sceats, 1981). The first source, however, does not include fertility questions at most enumerations, and the second is only a limited source of information on births.

The nature of and access to census data restricted its use in social scientific analysis. Not only was retrospective information on life-cycle events not collected, but the data is not available at individual level. Although aggregate level data from the censuses have been valuable for policy purposes, they can not enhance our understanding of the links between individual behaviour and the process of family formation dynamics.

The survey of New Zealand Women: Family, Employment and Education, carried out in late 1995, provides the opportunity to fill this gap. Women aged 20 to 59 at the time of the survey were identified for a face-to-face interview. This age span includes women of the older age groups who are the first generation of New Zealand women to have had a full reproductive life-cycle experience with hormonal contraception. They are also likely to have experienced both a completed reproductive cycle and increased labour force participation.

A sample of 2,500 women was drawn from about 250 clusters, using a stratified multi-stage probability sample proportional to size at each stage (Dharmalingam, HillcoatNallétamby and Pool, 1995). A further statistically refined over-sampling of Maori was carried out, using exactly the same multi-stage procedure in which all eligible women were interviewed, but continued only if the women responded Maori to a question on ethnicity. The data presented in this article are drawn from both the main sample and the oversample of Maori.

The questionnaire was drawn from the core and module versions designed by the Population Activities Unit of the United Nations Economic Commission for Europe from 1991 onwards for a project in a number of ECE countries, including the United States and Canada. One of the principal aims of this project has been to generate internationally comparable sample survey information on fertility and the family (UN, 1992).

The New Zealand questionnaire provides comprehensive data for individual respondents, and limited information for all members residing in the latter's household at the time of the survey. Life-history events relating to employment, contraception, cohabitation, pregnancy histories, etc. were covered in the survey (UNFPA, 1993; Marsault et al., forthcoming). Whilst generally respecting the core sections, modules and tables of the original questionnaire (UN, 1993, 1992), the New Zealand questionnaire was adapted to include new questions on such aspects as the country of birth and ethnic identity. For reasons of comparability certain questions were formulated in accordance with categories drawn from the New Zealand 1991 Census (e.g. ethnic identity, education, religion, employment).

\section{Method}

For descriptive purposes, we employ the life-table technique to estimate the probability of the occurrence of two sets of events: first jobs and first live births. This technique is the most widely used, when the duration of exposure (time) and censoring have significant influence on the likelihood of the event occurring (Smith, 1980).

For multivariate analysis, we apply Cox's Proportional Hazard Models, which combines regression and life-table techniques (Cox, 1972). The general form of Cox's model is:

$$
h(\mathrm{t})=h_{0}(\mathrm{t}) \text { e } B_{j} \mathrm{X}_{1}+. .+B_{k} \mathrm{X}_{k}
$$

$h(t)$ is the hazard rate, defined as the probability of an individual experiencing an event at time $t$ given that the individual is at risk at that time. The baseline hazard is $h_{0}(\mathrm{t})$ which can take any functional form. The ratio $h(\mathrm{t}) / h_{0}(\mathrm{t})$ for some values of the explanatory variables is called the relative risk. The regression coefficients in the above model are estimated by using the partial likelihood estimation method (Cox, 1972; Allison, 1984).

The dependent variable in the cox proportional model is the age at first birth which is measured in months. We have used six explanatory variables that are categorical. Table 1 provides a brief description of these variables. The information in the table shows that about a quarter of the respondents have no educational qualifications but about one-half have university or other tertiary level qualifications. The vast majority had worked for more than three years before they had either their first birth or survey date which ever came first. At the age of 15 , although the majority of respondents had lived in urban areas, significant proportions had lived most of their life either in rural areas or overseas.

\section{Results}

The life table estimates for age at first birth and for age at first job are given in Table 2 . We have used the simple summary measures of first quartile, median and trimean by current age. This is provided separately for Maori and Non-Maori. It is clear from Table 2, that there is a significant difference in the average age at first birth between Maori and nonMaori. The difference is more pronounced for the younger cohorts than for the older cohorts. For instance, the trimean 
Table 1: Variables used in the regression analysis and their percentage distribution.

\begin{tabular}{|c|c|c|}
\hline Birth Cohort & $\%$ & Description \\
\hline Before 1945 & 16.1 & Year in which the respondent was born \\
\hline 1945-64 & 60.2 & \\
\hline $1965-75$ & 23.7 & \\
\hline \multicolumn{3}{|c|}{ Number of years worked before first birth/survey date } \\
\hline Never worked & 6.6 & Information on all jobs that lasted for 3 or more \\
\hline $1-2$ years & 11.1 & months was collected with distinction between part-time \\
\hline $3+$ years & 82.3 & and full-time employment \\
\hline \multicolumn{3}{|c|}{ Completed Education } \\
\hline No qualifications & 24.0 & Highest completed educational qualification at the \\
\hline Secondary & 25.8 & time of the survey \\
\hline Tertiary & 50.2 & \\
\hline \multicolumn{3}{|c|}{ Residence at 15 yrs of age } \\
\hline Overseas & 16.7 & Place of residence at which the respondent spent most of her life \\
\hline Urban & 65.4 & up to age 15 \\
\hline Rural & 17.9 & \\
\hline \multicolumn{3}{|l|}{ Ethnicity } \\
\hline Maori & 10.6 & Ethnicity definition as defined in the census \\
\hline Non-Maori & 89.4 & \\
\hline \multicolumn{3}{|c|}{ Contraception at first intercourse } \\
\hline Not used & 46 & Use of contraception at first sexual intercourse \\
\hline Used & 54 & \\
\hline
\end{tabular}

Source: New Zealand Women Survey, 1995 (Number of observations: 2493)

Table 2: Life-table estimates for age at first birth and age at first job by current age and ethnicity:

\begin{tabular}{|c|c|c|c|c|c|c|c|c|}
\hline \multicolumn{5}{|c|}{$\begin{array}{l}\text { Non-Maori: Age at First Live Birth } \\
\text { (number of observations: } 2229 \text { ) }\end{array}$} & \multicolumn{4}{|c|}{$\begin{array}{l}\text { Maori: Age at First Live Birth (number of } \\
\text { observations: } 444 \text { ) }\end{array}$} \\
\hline & $\begin{array}{l}\text { 1st } \\
\text { Quartile }\end{array}$ & $\begin{array}{l}\text { 2nd } \\
\text { Quartile }\end{array}$ & Trimean & & $\begin{array}{l}\text { lst } \\
\text { Quartile }\end{array}$ & $\begin{array}{l}\text { 2nd } \\
\text { Quartile }\end{array}$ & Trimean & \\
\hline $20-24$ & 22.3 & - & - & $20-24$ & 19.3 & 22.4 & - & \\
\hline $25-29$ & 22.6 & 26.5 & 26.2 & $25-29$ & 18.4 & 21.6 & 21.6 & \\
\hline $30-34$ & 22.9 & 26.7 & 26.9 & $30-34$ & 19.1 & 21.0 & 21.4 & \\
\hline $35-39$ & 22.4 & 25.8 & 26.1 & $35-39$ & 18.7 & 21.5 & 22.4 & \\
\hline $40-44$ & 21.6 & 25.2 & 25.7 & $40-44$ & 19.0 & 21.1 & 20.9 & \\
\hline $45-49$ & 21.7 & 24.8 & 25.1 & $45-49$ & 18.4 & 21.0 & 21.1 & \\
\hline $50-54$ & 21.5 & 23.8 & 24.0 & $50-54$ & 20.1 & 21.7 & 22.0 & \\
\hline $55-59$ & 21.8 & 23.7 & 24.2 & $55-59$ & 20.1 & 21.6 & 22.0 & \\
\hline \multicolumn{5}{|c|}{$\begin{array}{l}\text { Non-Maori: Age at First Job } \\
\text { (number of observations: } 2229 \text { ) }\end{array}$} & \multicolumn{4}{|c|}{$\begin{array}{l}\text { Maori: Age at First Job } \\
\text { (number of observations: } 444 \text { ) }\end{array}$} \\
\hline $20-29$ & 16.7 & 17.9 & 18.1 & $20-29$ & 16.3 & 18.0 & 18.1 & \\
\hline $30-39$ & 16.5 & 17.6 & 17.8 & $30-39$ & 15.8 & 16.9 & 17.0 & \\
\hline $40-49$ & 17.0 & 17.2 & 17.6 & $40-49$ & 15.5 & 16.3 & 16.4 & \\
\hline $50+$ & 15.7 & 16.7 & 16.9 & $50+$ & 15.5 & 16.4 & 16.7 & \\
\hline
\end{tabular}

Source: New Zealand Women Survey, 1995 
for age at first birth for Maori aged 20-29 is about 21 years compared to about 26 years for non-Maori. Indeed, among non-Maori aged 20-24, 50 per cent had not had their first birth at the time of survey, whereas 50 per cent of Maori had.

Cohort differences in age at first birth are quite evident for non-Maori but not for Maori. For Maori, the trimean has remained around 21 years, whereas for non-Maori it has consistently increased from about 24 years for the birth cohort 50-59 to about 26 years for the younger cohorts. These observations on the change in age at first birth over time, and the ethnic differentials are consistent with the aggregate level data from the census and vital registration (Jackson and Pool, 1994).

With respect to the age at starting the first job (second panel in Table 2), the average age is around 18 years for the younger cohort which is up by about a year from the ages reported by oldest cohorts. The ethnic differential in age at first job is marginal. In fact, the trimeans for age at first birth for the age group 20-29 years are identical between Maori and non-Maori.

Of greatest interest in this table, however, is the comparison

Table 3: Life-table estimates for the age at first intercourse by current age and ethnicity:

\begin{tabular}{lllll}
\hline Age & $\begin{array}{l}\text { Non-Maori } \\
\text { 1st Quartile }\end{array}$ & Median & $\begin{array}{l}\text { Maori } \\
\text { 1st Quartile }\end{array}$ & Median \\
\hline $20-24$ & 15.8 & 17.6 & 15.3 & 16.4 \\
$25-29$ & 16.3 & 17.5 & 15.6 & 17.0 \\
$30-34$ & 16.5 & 18.1 & 15.6 & 17.2 \\
$35-39$ & 16.9 & 18.1 & 16.3 & 17.2 \\
$40-44$ & 17.1 & 18.7 & 16.4 & 17.3 \\
$45-49$ & 18.0 & 19.6 & $* 16.3$ & $* 17.9$ \\
$50-54$ & 18.2 & 20.3 & $* 16.6$ & $* 20.2$ \\
$55-59$ & 19.4 & 21.2 & $* 18.2$ & $* 19.3$ \\
$*$ Less than 40 cases & & & \\
Source: New Zealand Women Survey, 1995 & & & \\
\hline
\end{tabular}

Table 4. Percentage distribution of age at first intercourse, and percent using contraception at that time(of women ever exposed) by current age and ethnicity:

\begin{tabular}{|c|c|c|c|c|c|}
\hline $\begin{array}{l}\text { Current } \\
\text { Age }\end{array}$ & $\begin{array}{l}\text { Age at 1st } \\
\text { Intercourse }\end{array}$ & $\begin{array}{l}\text { Non-Maori } \\
\text { Distribution } \\
\text { (\%) }\end{array}$ & $\begin{array}{l}\text { Use } \\
(\%)\end{array}$ & $\begin{array}{l}\text { Maori } \\
\text { Distribution } \\
\text { (\%) }\end{array}$ & $\begin{array}{l}\text { Use } \\
(\%)\end{array}$ \\
\hline \multirow[t]{5}{*}{$20-29$} & $<17$ & 48 & 67 & 63 & 40 \\
\hline & $17-19$ & 38 & 77 & 34 & 48 \\
\hline & $20+$ & 15 & 75 & 3 & $60 *$ \\
\hline & All (\%) & 100 & 72 & 100 & 44 \\
\hline & $(\mathrm{N})$ & (454) & - & (154) & - \\
\hline \multirow[t]{5}{*}{$30-39$} & $<17$ & 32 & 50 & 51 & 34 \\
\hline & $17-19$ & 47 & 70 & 36 & 32 \\
\hline & $20+$ & 21 & 70 & 13 & $39 *$ \\
\hline & All (\%) & 100 & 63 & 100 & 29 \\
\hline & $(\mathrm{N})$ & (671) & - & (138) & - \\
\hline \multirow[t]{5}{*}{$40-49$} & $<17$ & 19 & 38 & 32 & 23 \\
\hline & $17-19$ & 46 & 55 & 45 & 24 \\
\hline & $20+$ & 35 & 62 & 23 & 12 \\
\hline & All (\%) & 100 & 54 & 100 & 21 \\
\hline & $(\mathrm{N})$ & (631) & - & (109) & - \\
\hline \multirow[t]{5}{*}{$50-59$} & $<17$ & 12 & 22 & \multirow{5}{*}{\multicolumn{2}{|c|}{ (See above 40-59) }} \\
\hline & $17-19$ & 29 & 32 & & \\
\hline & $20+$ & 59 & 55 & & \\
\hline & All (\%) & 100 & 44 & & \\
\hline & $(\mathrm{N})$ & (350) & - & & \\
\hline
\end{tabular}

* Fewer than 20 respondents

(N) Number of observations

Source: New Zealand Women Survey, 1995 
between the age at starting the first job and age at first birth. As can be seen, this interval widens with the age at starting the job and remaining relatively stable but the age at first birth increasing significantly. This simple empirical fact underlies many of the points we will raise later in the paper.

Table 3 gives age at first intercourse, and whether or not contraception was used is given in Table 4. These are analysed further elsewhere, but suffice to say that the age at first intercourse is earlier for younger cohorts, whereas the proportion using contraception increases dramatically for younger cohorts. Not only is overall usage greater for younger cohorts, but a higher proportion of users (the overwhelming majority) use efficient methods, whereas a significant percentage of older women employed less efficient methods (Dharmalingam and Pool, 1996).

Estimated coefficients for parameters in the Cox model are presented in Table 5. Model 1 provides the estimates for the additive effects of all the individual level and background variables. In model 2 we have included the interactions between birth cohort and work duration. Parameter estimates are presented in the form 'relative risks' or odd ratio which makes the interpretation easier. The estimated relative risk for the reference category of a factor is always 1.00 . A relative risk (or hazard ratio) of 1.00 is interpreted as indicating no difference in the probability of experiencing the event at any given age (or time of exposure-this is, in our case, the time elapsed between birth and the event), between the reference category and the referent category. Any value over 1.00 means that the referent category is more likely to experience, and any value less than 1.00 means the referent category is less likely to experience.

As the multivariate results from model 1 in Table 5 show, almost all variables included in the model seem to have significant effects on the likelihood of having a first birth at any age. The effects of birth cohort are, however, particu-

Table 5: Estimates of hazard ratio (relative risk) for the Cox proportional models for age at first birth.

$$
\text { Model } 1 \quad \text { Model } 2 \text { (with interactions) }
$$

Variable Additive effect Additive Effect Interaction with work duration

Work before first birth:
Not worked $\quad 1.00$

1-2 yrs $\quad 1.77$ (5.57)

$3+\mathrm{yrs} \quad 0.31(14.02)$

\section{Education}

No qualification 1.00

Secondary $\quad 0.78(3.67)$

Tertiary $\quad 0.69(6.17)$

University $\quad 0.34(11.71)$

Residence at 15 yrs

$\begin{array}{ll}\text { Overseas } & 1.00 \\ \text { Urban } & 1.39(5.09) \\ \text { Rural } & 1.41(4.38)\end{array}$

Ethnicity

Non-Maori $\quad 1.00$

Maori $\quad 1.25(2.87)$

$1.27(3.04)$

$1.92(2.53)$

0.44 (3.99)
-

$0.77(3.90)$

0.68 (6.42)

$0.32(12.01)$

\section{1-2 yrs $3+\mathrm{yrs}$}

- $\quad-$

Birth cohort

Before 1945

1945-54

1955-64

1.00

1965-75

$0.91(1.47) @$
$0.85(2.49)$
$0.76(3.26)$

-

$1.17(0.68) @$

1.51(1.73)@

2.18 (2.43)

$0.85(0.52) @$

$0.98(0.07) @$

0.69 (1.47)@

$0.76(3.26)$

Contraception at first intercourse

Not used

1.00

Used

0.83 (3.95)

$\overline{0.82}(4.18)$

Number of observations: 2429

* Unless otherwise indicated, all coefficients are significant at .001 level @ Statistically not significant at 0.05 level

() Number in parenthesis is z-statistic

- Not applicable

Source: New Zealand Women Survey, 1995 
larly strong and significant. The younger birth cohorts are at a lesser risk of having a first birth at any given age than the older cohort born before 1945. For instance, those born during the period $1965-75$ are about 25 per cent less likely than those born before 1945 to have a first birth for a given age.

Ethnicity and place of residence at age 15 years (just before the age the events we analyse here are taking place) are the only community background variables we included in the model. They also had significant effects on the timing of first birth. Holding everything else constant, the likelihood of having a first birth for Maori is about 1.3 times greater than for non-Maori. Similarly, those who spent most of their childhood (up to age 15) in rural or urban New Zealand had a greater likelihood of having a first birth at any given age than those who lived overseas.

The three individual level characteristics incorporated into our model are duration of work before having a first birth, current level of completed educational qualifications and use of contraception at first sexual intercourse. The frist two variables, work and education, have had the most powerful influence on the hazard rate. In general, those with high educational qualifications (tertiary and university) were less likely to have a first birth at any age than those without any qualifications. Those with tertiary level qualifications had a much lower risk than those with a secondary level educations. As expected, use of contraception at first intercourse delays having the first birth. It is possible that those who used contraception at first intercourse are more likely to go on to get education and/or employment without break before having a first birth.

\section{Work experience}

The variable we have particular interest in is work experience. We first introduced nine work duration categories in the model. But as the categories for durations for over three years did not show much variation in relative risks, we collapsed the entire work duration into the three major categories used here. As Table 5 shows, work is the single most powerful factor in influencing the timing of first birth. Moreover, the effect is not monotonic. Compared to those with no work experience, one to two years of work experience increases the risk of having a first birth by a factor of 0.77 . But, the risk for those with work experience for three or more years decreases by a factor of 0.69 . In other words, exposure to work increases the risk initially and then operates in the opposite direction. This could mean that if an individual has not had a birth in the initial years of work, her chances of having a first birth is much less as the work duration increases. This fits the axiom of cumulative inertia well-known to students of mobility.

It is possible for work experience to interact with the ideational effects coming from belonging to a particular birth cohort. That is, the effect of 1-2 years work duration may vary (not remain constant) across birth cohorts. The interaction between work duration and birth cohort is taken into account in Model 2. Estimates for the parameters in model
2 reflect the interaction effects. Additive effects of the explanatory variables in model 2 remain as strong and significant as they were in model 1 without interaction terms. What is interesting, however, is that only the 1945-54 birth cohort women had a higher risk of having a first birth in the first two years of work. The youngest cohort, 1965-75, had a lower risk than the rest, irrespective of work duration. All the additive effects for the variable birth cohort have become statistically insignificant which suggests that its operates mainly through work variable.

\section{Discussion}

In an era in which the movement of women into the paid workforce has had a major impact on the supply and demand of labour one of the more critical issues for both labour market and new household economics is how childbearing andwork interact. This paper has investigated this key issue. We have concentrated here on one direction only - showing the effect of labour supply decision on child-bearing. Nevertheless this apparently simple relationship is itself a function of complex social-demographic changes to which industrialised economies have been subject. To explain the narrower labour and employment implications it is necessary to discuss this wider context.

Almost all developed countries have experienced what van de Kaa (1987) calls the second demographic transition. The low fertility levels of the pre-World War II period were followed by the baby boom, and then in the second demographic transition rates dropped again to replacement level fertility. Although current fertility for Maori and non-Maori is around replacement level, the historical pattern of nonMaori has been very close to the Western European and North-American trends. This broad similarity in the timing and nature of fertility change has meant that the underlying causes of transition could also be similar, although the importance of a specific cause could vary.

Traditional explanations for demographic change in the Western world (including North America, Australia and New Zealand) center around industrialization, urbanization, and value shifts, and the accompanying changes in family structures and gender relations. The increased independence of women in the second half of this century has been facilitated by numerous underlying major forces of change, but is most clearly manifested in their increased participation in the paid labour force and at higher levels of education.

Demographers have always been interested in the influence of period and community factors, the individual level variables and cohort effects on fertility. In this paper, we have attempted to analyse the influence of each of these factors on the timing of first live birth for New Zealand women. Our findings reiterate the point that, over the years, women in New Zealand have progressively delayed having their first baby. This is particularly so for non-Maori women. Moreover, Maori have their first birth at a relatively early age compared to non-Maori.

What is striking are the results from the multivariate analysis: work and education mediated by the use of contraception 
have a substantially greater effect on the timing of first birth than the other variables. While the relationship between education and timing of first birth is along the expected direction, this is not entirely so for work experience. An average individual has a greater risk of having a first birth in the first few years of work than when either not working or working for over two years. This is particularly true for older cohorts.

In an analysis of first marriages we found that having a first birth before marriage greatly increased the risk of marriage (Dharmalingam et al., 1996). But work experience had the opposite effect. It appears that not only is work important for each of the life cycle events separately, but also it is possible for work to have cumulative effect in the entire process of family formation.

Overall, the cohort to which women belonged was a powerful factor. This very much fits an earlier analysis of ours relating to the shift to cohabitation. If this had also been the most powerful effect Murphy's hypothesis - changes in the attitudes and norms towards the acceptance and actual use of contraception is more important for fertility decline than socio-economic change - discussed earlier, would been sustained. In fact, the effect of a women belonging to a particular birth cohort depends on whether she works or not, and how long she has been working. In general young women who were working were much less likely than nonworking women to have a first birth at any given age. What is even more interesting in terms of relative risks, however, is that the strongest factors were education and work duration, which were inversely related to chance of conception. In a sense this last finding challenges Murphy's work

\section{Further research}

As stated at the beginning, we have looked at the effect of work on the timing of first birth. An equally important approach is to study the effect of the timing of first birth on work: the influence of child-bearing on labour supply. This could be expanded to cover the effects on work of the timing of births of various orders (e.g. first, second, third etc) and the total number of births. We hope to address these issues in our future research.

In this paper we have assumed that a woman's decision to work influences the decision to have a first birth. However, it is possible that some women work because they have not been successful in having a baby. The data we have does not allow us to examine this.

\section{Acknowledgement}

We are grateful to the following agencies for funding the project on which the analysis reported in this paper is based: FRST, Te Puni Kokiri, Ministry of Health, Ministry of Women s Affairs, Social Policy Agency and Midland Regional Health Authority.

\section{References}

Allison, P. D. 1984 Event history analysis. Regression for longitudinal event data. Newbury Park: Sage Publications.

Bongaarts, J. 1993 The supply-demand framework for determinants of fertility: an alternative implementation, Population Studies 47(3): 437-456.

Becker, G. 1960. An economic analysis of fertility. In R. Easterlin(ed.) Demographic and economic change in developed countries, Princeton: Princeton University Press.

Becker, G. 1981 A Treatise on the Family, Cambridge, Mass.: Harvard University Press.

Cleland, J. and C. Wilson 1987 Demand theories of fertility transition: an iconoclastic view. Population Studies 41: 5-30.

Cox, D. R. 1972 Regression models and life tables (with discussion). Journal of the Royal Statistical Society 34: 187-220.

Dharmalingam, A. and I. Pool 1996 Age at first intercourse in New Zealand. Paper presented at the Conference of the Australian Population Association, Adelaide, Australia, 4-6 December.

Dharmalingam, A., S. Hillcoat-Nallétamby and I. Pool 1995 Survey on family formation and associated factors: A brief introduction. Discussion Paper No.9, Population Studies Centre, University of Waikato, Hamilton.

Dharmalingam, A., S. Hillcoat-Nallétamby, I. Pool and K. Johnstone 1996 Entry to first conjugal unions in New Zealand. Revolution or continuity?: Preliminary results . Paper presented at the Conference of the European Society for Population Economics, 10th Annual Meeting, Uppsala, Sweden, June 13-15.

Easterlin, R. 1978 The economics and sociology of fertility: a synthesis. In C. Tilly (ed.) Historical Studies of Changing Fertility, Princeton: Princeton University Press.

Jackson, N. and I. Pool 1994 Fertility and family formation in the Second Demographic Transition: New Zealand patterns and trends. Family and society change: Research Report No.2, New Zealand Institute for Social Research and Development Ltd., Wellington.

Knodel, J. And E. van de Walle 1979 Lessons from the past: policy implications of historical fertility studies, Population and Development Review 5(2): 217-245.

Marsault, A., I. Pool and S. Hillcoat-Nallétamby (forthcoming). Women: Family, Employment and Edu- 
cation Survey 1995, Technical and methodological report Population Studies Centre, University of Waikato, Hamilton.

Mauldin, P. and J. A. Ross 1991 Family planning programs: efforts and results, 1982-1989, Studies in Family Planning 22(6): 350-367.

Murphy, M. 1993 The contraceptive pill and women S employment as factors in fertility change in Britain 1963-80: a challenge to the conventional view Population Studies 47: 221-243.

Pool, I. 1991 Te Iwi Maori. Auckland: Oxford University Press.

Pool, I. and J. Sceats 1981 Fertility and family formation in New Zealand. An examination of data collection techniques and analyses. Report Wellington: Ministry of Works and Department.

Willis, R. J. 1974 Economic theory of fertility behaviour. In T. W. Schultz (ed.) Economics of the family, marriage, children and human capital, Chicago: Chicago University Press.

Smith, D. 1980 Life table analysis. Technical Bulletin No.6. World Fertility Survey, London.

van de Kaa, D. J. 1987 Europe's second demographic transition. Population Bulletin 42 (1).

van de Kaa, D. J. 1996 The second demographic transition, The W. D. Borrie Lecture, Australian Population Association Conference, Adelaide, 3 December.

van de Walle, E. 1992 Fertility transition, conscious choice and numeracy, Demography 29(4): 487-502.

\section{Authors}

A. Dharmalingam is a lecturer in the Population Studies Centre, Ian Pool is professor and Kim Johnstone is a research fellow in the Population Studies Centreas well as project manager for health status reports at the Midland Regional Health Authority, Hamilton. 